Iryna Kyryliuk,

Ph.D. (Economics), Associate Professor, PavloTychynaUman State Pedagogical University, 2, Sadova str., Uman, Cherkasy region, 20300, Ukraine, ORCID: 0000-0001-9814-195X

ResearcherID: F-9440-2018

\title{
FORMATION OF TOURIST CLUSTER AS A WAY TO ECONOMIC GROWTH OF THE REGION
}

The article explores the issues of clustering as an effective mechanism for improving competitiveness. The trends that contribute to the implementation of the cluster approach in tourism and the main benefits of creating such clusters are identified.

Keywords: cluster policy, region, tourism, tourist destination, tourist cluster.

Relevance of research topic. In the context of globalization and structural restructuring of the economy, intensification of national and world competition, as well as the spread of integration tendencies, tourism plays an important role in overcoming the crisis in the country's economy, as it is an important factor in the socio-economic development of the regions. The positive tendency of the development of domestic tourism, which has been observed in recent years, provides for an increase in the level of employment of the population, earnings of investment flows to the regions, filling of state and local budgets.

The creation of tourist clusters in different regions of the country is a promising trend and has a positive impact on the development of regional tourism. In recent years, the need to solve the problem of forming new approaches to the creation of tourist clusters which has become especially urgent, so, the issue of the creation and functioning of tourist clusters as a basis for enhancing the tourist attractiveness of the region is urgent and needs further study.

Formulation of the problem. One of the factors of the organization of hightech production and a way of increasing the efficiency of using regions' tourism and recreational resources is the formation of tourism cluster entities of sectoral and interbranch character.

The main consumer of tourist services is the tourist who forms requirements for the tourism product. Looking at this, the degree of satisfaction of the spiritual, emotional needs of the tourist determines the level of competitiveness in the industry. 
When forming a tourism cluster at any territorial level, it is necessary to take into account that insufficient level of development of at least one of the components of the tourism infrastructure can negatively affect the overall tourist's impression from visiting the tourist and recreational region. Therefore, the task of the tourism cluster is to successfully promote the tourism product market and to achieve a common economic result through the effective management and implementation of marketing communications and the collaboration of related businesses and institutions, which in common share tourism resources, specialized tourism infrastructure, local labour markets. The business activity of economic entities operating in the region directly affects the pace and sustainability of its socio-economic development in the uncertain conditions of the market environment.

Analysis of recent researches and publications. Scientists such as: M. Porter, O. D. Kol, I. I. Potapova, Ye. V. Vidishcheva, V. F. Danylchuk and others were engaged in research of problems of creation, functioning and development of clusters. Problems of efficiency of tourist clusters, strategic vision of the industry development are the subject of research of such scientists: N. Andrusiak, D. Didenko, O. Kuzmina, S. Nordin, D. Proskury, S. Sokolenko, I. Shymakovoi and others. However, despite the wide range of research findings of the above authors, it should be acknowledged that the problem of regional cluster formation at the regional level is insufficient.

Presenting main material. Clusters around the world are considered to be an effective means of generating national competitive advantages, enhancing production efficiency through the vertical and horizontal integration of both industries and enterprises. The active interaction of all members of the tourism cluster allows to obtain the overall result - a complex tourism product that is competitive in the international market of tourist services, which cannot be obtained from the isolated operation of every element of this system.

In the process of cluster development, a synergy effect is particularly evident, which allows to obtain an overall effect that is not equal to the sum of the effects of the isolated operation of each element of the system. For the development and operation of the tourism sector on a regional scale, the cluster synergistic effect will be achieved more quickly due to the closeness and close contact of the cluster members, which in turn will promote tourism in the region.

The creation, formation and operation of a regional tourism cluster is always linked to the emergence and manifestation of a growing effect, first of all, synergistic, which provides quantitative and qualitative growth for many components of the socioeconomic development of the region, which in turn contributes to improving the competitiveness of the region as a whole. The regional cluster plays a leading role in the process of activation of innovative development in the tourism region's industry, since its activities optimize the performance of production systems, development is activated for high-tech and knowledge intensive industries, take advantage of company 
specialization, creating on this basis a powerful synergistic effect of socio-economic growth at both regional and national levels. M. Porter defines: clusters are geographically concentrated groups of interconnected companies, specialized suppliers, service providers, firms in related industries, also related organizations (universities, standardization agencies, trade associations) in certain industries that compete with each other but work together [8, p.256] (Porter,2005).

The tourism cluster is different from the manufacturing one because the tourism industry has its own characteristics therefore, it requires the integration of the efforts of enterprises of many types of economic activity in the process of forming a complex tourist product competitive in the international market of tourist services.

There is no unity among scientists in the interpretation of this concept. Some authors consider the tourism cluster as a socio-economic system [1] (Bakurova, Didenko\&Popova, 2011), others - as a complex of geographically localized and interconnected business structures of different industries [2; 6] (Havryliuk\&Okhrimenko, 2015; Kol',2010), there are also views on the tourism cluster as a system of intensive production, technological and information interaction or the optimal form of social dialogue [3; 7] (Hontarzhevska, 2006; Krainyk\&Bil, 2009). In our opinion, all definitions reflect the characteristic features of the tourist cluster, which unites the efforts of all its participants, aimed at the process of creating a competitive tourism product with the aim of increasing tourist flows to the region and meeting the requirements of each consumer of tourist services.

The functioning of the tourism cluster, which is a form of concentration in the region of tourism components, creates opportunities for fuller utilization of the tourism and recreational potential of the region through the formation of network links between businesses that are geographically concentrated in its territory and involved in the formation, promotion and sale of tourism products. It promotes the development of tourist destinations.

Cluster formation can be carried out by several approaches: evolutionary, institutional, resource-technological, geographical, qualitative, behavioural, structural, managerial, systemic, strategic. The factors that influence the development of the tourist cluster are conditionally distinguished:

1. Resources - the foundation on which the success of any tourism business, including the tourism cluster, is built. Resources are divided as follows:

- natural resources, attraction resources, fashion trends, pilgrimage, other resources, objects that underlie the tourist product;

- human resources - a necessary resource for servicing the tourist product;

- financial resources - ease and accessibility to various sources of investment;

- informational resources - a source for facilitating access to information, making the right organizational decisions, prospects for strategic cluster development, implementation of innovative technologies, etc.; 
- scientific and technical resources received by the cluster members, availability and quality of the research received;

2. Ancillary industries that indirectly influence the development of the tourism cluster, but without which the cluster will not be able to function effectively;

3. Administrative barriers: fiscal policy, criminal situation, anything that prevents cluster creation and development;

4. State authorities: levers of influence, regulations, laws, on the one hand, on the other - support and promoting cluster development. For tourism businesses, cluster membership allows you to: gain greater access to information on various aspects of the activity; opportunities to enter the national or world market; attracting investment to improve service quality and enhance competitive advantage; access to legal and marketing advice; participation of the management of tourism enterprises in seminars conducted to familiarize themselves with the peculiarities of doing business. The cluster approach offers several advantages (institutional, innovative, performance enhancing), at the expense of which provides economic growth, attracting foreign direct investment, solving the problem of employment. The main advantages of the cluster model of organization of tourist activity of national enterprises are:

- increase of economic efficiency and competitiveness of joint activity of the enterprises integrated into the tourism cluster compared to the separate activity;

- reducing the cost of services through the sharing of tourism resources and tourism infrastructure, expanding the range of competing suppliers and consumers of tourism services, development of cooperation, contractual specialization;

- stimulating innovative development, expanding access to innovation by increasing the inter-firm flow of ideas and information;

- formation of a local sectoral labour market that allows for the exchange of employees, their internships, advanced training; improving the investment attractiveness of the regions;

- the clustering of tourism with proper organization stimulates the growth and development of other industries;

- cluster technologies help to establish links between state and business circles in solving economic problems of regions [5] (Kalchenko, 2009).

Location in one region of accomplices allows you to quickly set goals, objectives and make the necessary decisions on existing problems. The effective activity of a cluster is determined by the nature of the relationship of its potential participants with regional governing bodies.

The cluster approach provides authorities with the tools to interact effectively with business, a deeper understanding of its characteristic indicators and tactical objectives, possibility of purposeful, real and motivated strategic planning of regional resources, development of territories. Successful implementation of cluster policy selfgovernance by regional authorities requires interconnected and coherent regional 
development strategies and strategies for the development of individual clusters. Regional authorities should be interested in integrated socio-economic development of the territories, ensuring normal living conditions of the population, creating clusters and achieving their effective structure.

When forming a cluster strategy, the type of cluster construction should be taken into account: geographical, horizontal, vertical, lateral, technological, focal, qualitative. Recreational tourism is characterized by the combination of several industries or sectors of the economy. This indicates the priority of horizontal type of construction of recreational and tourist clusters.

In order to develop a tourism cluster in the region, an active cluster policy is needed, which could provide for the removal of various barriers on the one hand and facilitate the expansion and strengthening of cross-sectoral and intersectoral links on the other.

Cluster policy should be understood as a set of government regulation measures taken by public authorities to enhance the competitiveness of the country's economy by creating conditions for cluster development. Cluster policy is one of the tools of regional development and therefore should stimulate business initiative at the regional and local levels.

The main tasks of the state's cluster policy should be:

- creation of favourable conditions for effective organizational development of clusters, including identification of potential cluster participants, removal of certain restrictions, ensuring increase of competitive advantages of cluster participants;

- coordination of activities of local executive authorities and business associations in the implementation of cluster policy;

- ensuring effective methodological, information-consulting and educational support for the implementation of cluster policy at regional and sectoral levels;

- ensuring effective support for projects aimed at enhancing the competitiveness of cluster participants, taking into account cluster development priorities [4] (Davydenko,2018).

The state's supportive cluster policy focused on the development of tourism infrastructure in the region, stimulating innovation, initiating educational programs, projects for tourism business entities, the introduction of certain privileges and preferences to stimulate business development is a prerequisite for the effective development of the tourism cluster.

Conclusion. The regional cluster plays a leading role in stimulating the innovative development of the tourism industry in the region, since its activities optimize the performance of production systems, the development of high-tech and knowledge-intensive industries, the benefits of company specialization are used, creating on this basis a powerful synergistic effect of socio-economic growth, both at the regional and national levels. The creation, formation and operation of a regional 
tourism cluster is always associated with the emergence and manifestation of a growing effect, first of all, synergistic, which provides quantitative and qualitative growth of many components of the socio-economic development of the region, which in turn contributes to increasing the competitiveness of the region as a whole.

To increase the efficiency and functioning of the regional tourism cluster requires an organizational and economic management mechanism, the basis of which is the alignment of goals and objectives with the methods and means of achieving the intended results of the implementation of decisions. The important function of the organizational and economic management mechanism is the formation of fundamentally new approaches to adaptation of cluster members to interaction, cooperative communication, readiness to develop forms and methods of internal network cooperation.

\section{REFERENCES}

1. Bakurova, A. V., Didenko, A.V. \& Popova, O. Yu. (2011). Optimization of tourist enterprises in the formation of an inter-regional cluster. Economy. Management. Innovation, n 1(5). Retrieved from http://tourlib.net/statti_ ukr/bakurova2.htm.

2. Havryliuk, S. P. \& Okhrimenko, A. H. (2015). Conceptual and terminological identification of the regional tourist cluster. Carpathian region, n 1-2, pp. $280-288$.

3. Hontarzhevska, L. I. (2006). Foreign economic activity of tourist enterprises of Ukraine. Extended abstract of candidate's thesis. Kyiv. p. 21

4. Davydenko, I. V. (2018). Tourist clusters as a direction of regulation of tourist business. Black Sea economic studies, Vol. 28(1), pp. 68-72.

5. Kalchenko, O. M. (2009). Clustering in the tourism industry. Bulletin of Chernihiv State Technological University, n 39, pp. 186-195.

6. Kol', O. D. (2010). Conceptual bases of formation of a cluster of tourist business structures on inbound tourism in a major city. Problems of the modern economy. Eurasian international scientific and analytical journal, n 1, pp. 379-383.

7. Krainyk, O. \& Bil M. (2009). The region's tourism cluster as a form of social dialogue: a managerial aspect. Scientific Bulletin «The democratic self-government», Vol. 4. Retrieved from http://tourlib.net/statti_ukr/ krajnyk.htm.

8. Porter, M. (2005). Competition. Trans. with english. Moscow: Vil'jams. $608 \mathrm{p}$. 